\title{
Green IS Does Not Just Save Energy - Insights from a Survey on Organizations' Uses of Sustainable Technologies
}

\author{
Helge Schmermbeck \\ University of Duisburg-Essen \\ helge.schmermbeck@uni-due.de \\ Joke Thünnesen \\ University of Duisburg-Essen \\ joke.thuennesen@uni-due.de
}

\author{
Natalie Voss \\ University of Duisburg-Essen \\ natalie.voss@uni-due.de \\ Frederik Ahlemann \\ University of Duisburg-Essen \\ frederik.ahlemann@uni-due.de
}

\begin{abstract}
Organizations are increasingly challenged to digitally transform themselves, and to respond to calls for increased sustainability. While the adoption of sustainable innovations, such as Green information systems (Green IS), are one way to address both challenges, there are only few insights that provide nontechnology or company-specific insights into specific positive and negative Green IS outcomes. We address this shortcoming and shed light on Green IS adoption outcomes, as well as their interconnection to general sustainability initiatives in organizations. In a descriptive survey we find that many organizations already employ sustainability principles, but few incorporate Green IS. We confirm organizations almost exclusively report positive outcomes of Green IS usage, such as reduced resource consumption, increased compliance with regulations, and social acceptance. Based on these findings we suggest to especially further research the process of Green IS adoption.
\end{abstract}

\section{Introduction}

Information technologies (IT), and Information systems (IS), as drivers and supporters of business innovations in globalized industrialization [15], significantly contribute to the welfare of societies and the development of economies. They also trigger one of the toughest, most imminent challenges for society: the preservation of the natural environment [23].

Producing IT goes along with mining of valuable and rare minerals, and processing toxic and hazardous materials, which have severe consequences for our soil and groundwater [12]. Their use increases energy consumption [24], resulting in higher greenhouse gas emissions [12]. Their obsolesce results in increasing electronic waste. Thus, the effects on the natural environment are becoming increasingly imminent. Atmosphere and ocean temperatures are rising, causing glaciers and polar caps to melt and sea-levels to rise; there has also been a marked increase in potentially dangerous weather-related phenomena [12, 23].

Hence, sustainability has become a topic in corporate management [20]. While it has many connotations and synonyms (e.g. eco-efficiency, ecoadvantage, or corporate responsibility), all definitions bring together the underlying paradigm to preserve an ecological but also a socio-economic system for future generations [7]. Research noted that sustainability enables individuals, organizations, governments, and society to transform toward environmentally sustainable practices [19]. Further, implementing green innovation may, especially for organizations, meaningfully contribute to performance, competitiveness, besides being a way to protect the natural environment [39].

Also in the IS domain researchers have begun to investigate the influence of sustainable innovations to address IT infrastructure and business process management challenges [28]. In recent years this has become closely connected to the terms Green IT and Green IS [18]. As principles and activities that "aim to decrease resource consumption" [21], Green IT is often only linked to the addressing of IT-related resource and energy consumption issues [7]. Green IS comprises measures and activities to minimize resource consumptions [4] as well as controlling, guiding, and communicating practices with direct (e.g. cost savings, competitive advantages) and indirect benefits (e.g., optimizing information production and processes) [21].

Research into Green IS has mainly been conceptual (e.g. the development of a research agenda for Green IT and IS) [13, 23], exploratory (e.g. the exploratory operationalization and development of measures for 
Green IT) [22], or focused on technological issues (e.g. building automation systems) [35]. Moreover, there has been little empirical research into Green IS, and it has only selectively highlighted the benefits of Green IS outcomes. Some studies found long-term benefits of general environmental performance [21] or highlighted organizations' environmental, social, strategic, and thus economic value [35], but relied on user perceptions. Others found green practices (e.g. recycling, energy management) are beneficial for organizations [25] or have benefits at the individual (e.g. adoption and routinization), organizational (e.g. competitive advantage), and/or societal levels (e.g. lower energy consumption and pollution) $[23,36]$.

There is a need for empirical research on demonstrable effects [23]. To provide a basis for further empirical work and to partially address these limitations, we catalog specific sustainability and Green IS actions [1, 2, 37], and describe how these translate into increased organizational sustainability [37]. As a conceptual base, we relied on a Green IS adoption framework that abstracts specific actions and outcomes on four levels: the natural environment, the society, the organization (as the adopting unit), and individuals [32].

In addition to these academic reasons, we chose to report on outcomes, because many organizations still resist integrating Green IS into long-term strategies [6]. Although there is principally willingness to adopt [34], Green IS adoption is primarily not pursued because organizations seem uncertain about Green IS benefits [19]. This paper hence, seeks to answer the research question: What are the outcomes of Green IS initiatives as part of organizations' general sustainability actions?

We chose to answer this practice-based research question [17] by descriptive reporting on companies and documenting their most undertaken sustainability and Green IS actions. A descriptive survey fits our goals best since we seek to report on both, positive and negative outcomes. Our insights into sustainability actions and outcomes, may also be achieved by current nonadopters and used as a basis for deeper research into the outcomes of sustainability and Green IS initiatives.

The remainder of this paper is structured as follows. We provide conceptual foundations for outcomes of sustainable innovations, and Green IS, and describe the research approach. Then we present our results, which we then discus and end with a conclusion.

\section{Conceptual Foundation}

\subsection{Sustainability Innovations}

Organizations seek to innovate themselves as well as their processes, products, and services. They try to differentiate from their competitors and ultimately to create a sustainable competitive advantage [4, 9]. Innovation - as the introduction of resources and/or development of capabilities that are new to an adopting organization [8] - is one way to achieve this goal. Organizations may, for instance, use process innovations to enhance their profitability by improving resource and energy utilization as well as by producing less waste [38]. They may also adopt novel IS that may prevent or minimize the resources being used and consumed. The use of digital invoices (rather than printed ones, with lower use of printers and printer cartridges) or video-conferences (instead of physical travel to meetings) can be new chances [35].

Traditional research into innovation adoption, or into sustainable innovations can be categorized by a focus on a single technology [e.g. 14], by taking an organizational [e.g. 28], or an individual perspective [e.g. 25]. Some studies have taken a phased approach, investigating factors that influence the pre-adoption [e.g. 30], adoption [e.g. 5], and outcomes [e.g. 19] of an innovation. Sustainable, or green innovations - as a set of technologies and practices that benefit both, an adopting institution [39] and the natural environment [35] - are a specific innovation class. They can be described in light of the many well-researched insights [e.g. 4, 8, 23], but need expansion to address emerging global than just organizational or societal challenges.

Recent research found green innovations, especially in the current digital business environment, differ from general innovations concerning the determinants of adoption. This is not limited to innovation', or technology characteristics [22], but also the subsequent innovation process [32], their performance and consequences of adopting them [39].

Organizational decision-makers must understand these competitiveness-related and sustainability-related implications, if they are to address them in use-related decisions [26]. In this way these implications can be fully integrated and used as an additional variable in general resource management [3].

\subsection{Green IS}

Green IS are a special category of sustainability innovations, as it requires a fairly long term to unfold its sustainability potential. This is due to IT equipment production causing the consumption of resources the emission of greenhouse gasses, and potentially more non-recycled waste [28]. On the other hand, IS can also be key to addressing these issues. It can help to prevent the creation of waste (e.g. by using digital documents) [21], to reduce the resources used (e.g. by videoconferencing [35]) and the energy used (e.g. reusing data center thermal emissions [e.g. 26]). 
Many studies have examined the concept or factors that influence organizations' adoption of Green IS [19]. They, for instance, ascertained that if organizations evaluate their sustainability portfolio, they will also evaluate Green IS [29]. Moreover, in organizations that have adopted Green IS, there is a positive alignment between general sustainability and Green IS [39].

Research also found, many organizations undertake specific Green IS initiatives to increase efficiency and using Green IS to reduce electricity, the use of physical resources, and waste emissions [14]. Also, IT-heavy organizations seem to focus on efficiency by virtualizing servers and data centers, or by improving the cooling of their remaining servers [7]. They also ascertained the outcomes of Green IS can be categorized [32] into the organizational level (e.g. increased IT operational efficiency [22]) or the individual level (e.g. improved social conditions for employees [22]), while others had sociological (e.g. increased awareness of sustainability [37]) or environmental outcomes (e.g. electricity, or greenhouse gas emissions savings [35]).

Few studies brought together these two streams. One we refer to took prevailing conceptual and empirical insights and abstracted them into a general Green IS adoption framework [32]. It is a first step toward a comprehensive picture on the determinants of sustainability, the adoption of Green IS innovation, adoption, and its outcomes. Especially the outcomes of Green IS adoption are of interest, since they seem to be the most appropriate way to evaluate the success of the adoption of innovation.

\section{Research approach}

\subsection{Study conceptualization and creation}

We chose a quantitative approach for the following reasons. First, we seek to confirm the selective insights into the maturity and diffusion of organizations' Green IS use [21, 27] and the outcomes of sustainability in institutions $[16,31,35]$. Second, we seek to confirm and enrich previous conceptual findings that frame organizational adoption and use of Green IS as a process. It is not only influenced by the factors of the adopting organization and its members, but also by society and the natural environment [32]. Third, we aim for high rigor and a sample that allows us to sufficiently categorize and investigate relationships within the generated data. Fourth, we chose breadth over depth in order to get potentially better generalizable results.

Publicly available data on sustainability tends to be hardly comparable, as it provides a superficial understanding of an organizations' environmental actions and outcomes [10], we chose to theoretically sample and question organizations directly. For this, we conceptualized and created a questionnaire that contains extracted and self-developed items and that addressed five constructs in six sections (see Table 1).

In section 1, the participants were welcomed. Section 2 was about respondents' demographic data, and organizations' characteristics. Section 3 contained questions about IT department characteristics. Section 4 asked about organizations' sustainability means, and Green IS adoption status. Section 5 contained questions about the outcomes of general and Green IS actions. Section 6, we thanked and dismissed the respondents.

Since not all studies contained detailed information about the specific items used, and since some were qualitative studies, the identified items needed to be modified or operationalized to fit our means. For instance, we took the job title descriptions [27], but extended the answer options to the job titles of CEO, Chief Financial Officer (CFO), Middle Managers, and Other. To fit the open question "Is there an environmental or sustainability action plan in your company?" [31] to our needs, we altered it to a closed three-point Likert scale (with the three options: 'Yes, a

Table 1. Construct overview

\begin{tabular}{|c|c|c|}
\hline Construct & Conceptualization & References \\
\hline $\begin{array}{l}\text { Use and administration of } \\
\text { sustainability }\end{array}$ & $\begin{array}{l}\text { The use, promotion, and support of general sustainability innovations, actions, and } \\
\text { processes in the organization that, based on its current economic and social structures, } \\
\text { seek to positively influence its environmental sustainability. }\end{array}$ & $\begin{array}{l}{[16,21} \\
27,31]\end{array}$ \\
\hline $\begin{array}{l}\text { Use and administrative } \\
\text { support of Green IS }\end{array}$ & $\begin{array}{l}\text { The use, promotion, and support of Green IS innovations, actions, and processes, as a } \\
\text { dimension of the organization's general sustainability actions, that seek to positively } \\
\text { influence its IT department, organizational structures, and external markets. }\end{array}$ & {$[7,27]$} \\
\hline Non-adoption of Green IS & The non-use or non-adoption of Green IS innovations, actions, or processes. & $\begin{array}{l}\text { Self- } \\
\text { developed }\end{array}$ \\
\hline $\begin{array}{l}\text { Status of Green IS } \\
\text { initiative }\end{array}$ & $\begin{array}{l}\text { The extent and maturity of the use, promotion, and support of Green IS innovations, } \\
\text { actions, and processes in an organization. }\end{array}$ & {$[7,27]$} \\
\hline $\begin{array}{l}\text { Outcomes of general } \\
\text { sustainability and Green } \\
\text { IS initiatives }\end{array}$ & $\begin{array}{l}\text { The outcomes of i) generally sustainability and ii) specific Green IS innovations, } \\
\text { actions, and process outcomes that affect the organization's environmental } \\
\text { sustainability. }\end{array}$ & {$[31,35]$} \\
\hline
\end{tabular}


corresponding strategy or directive has been implemented', 'No, but the implementation of such a strategy or directive is being planned', and 'No, an appropriate strategy or guideline has not been implemented and is not being planned'). We used specific questions ('Does your organization have a CIO?', 'Does your organization pursue a strategy to protect the environment or is there a sustainability policy?', and 'Does the environmental or sustainability policy cover the IT department?') as filter questions to direct respondents to only relevant questions.

With regard to a globalized working environment, we had the questionnaire translated into the lingua franca by an external non-native, yet fluent Englishspeaking researcher. Hereby, language barriers and misunderstandings could be avoided. We jointly reviewed and then implemented the translations in an online survey tool [19]. The pre-test of the questionnaire took place with a group of four researchers from the IS domain, two practitioners from an IT service provider, and a non-IT-related practitioner.

\subsection{Data Collection and Sample}

We searched and sampled for companies in Germany that had undergone any sustainability initiative (e.g. the use of environmentally certified products or practices), or also use Green IS. We identified the sample by means of websites that offer an overview of sustainably engaged companies. Blauer Engel is, for instance, an eco-label of the Federal Government and publishes a list of these companies. Through a purposive, confirmative (and thus theoretical) sampling frame, we identified companies i) linked to any sustainability initiative or ii) that produce or use environmentally friendly products or services. By this thorough evaluation basis, our results may also be tested, and further developed with a sample of companies that i) have not yet started a sustainability initiative or had contact with sustainable technologies, or ii) in which these or Green IS adoption had failed.

Since the study is intended to investigate general IS adoption outcomes as part of organization s' general sustainability initiatives, we asked for CIO, CFO, or Chief Green/Sustainability Officer (CGO/CSO) to fill out the questionnaire. We contacted the representatives either i) directly via personal e-mail, or ii) via the organization's general contact e-mail with a request for the material to be forwarded. All recipients received an invitation package with an invitation letter and a project description. They were ensured of our conformance with EU General Data Protection Regulation 2016/679 as well as of anonymous participation. We asked them to participate honestly and offered them to send the study report upon completion. The e-mail addresses were systematically saved separately. The survey period was November 14, 2018 to February 28, 2019. We contacted 850 companies $(\mathrm{N})$, received 105 clicks and 55 fully filled out (and thus valid) questionnaires (n) - a $6.47 \%$ response rate.

With especially Green IS as a relatively novel, and practice-based topic [33], we took the small sample as sufficient for a descriptive analysis [17]. We consequently did not aim for statistical theory testing, or significance analysis, but chose to document and outline potential trends within our data.

Most responses came from organizations of the services and craft or energy and environment sectors (each 5; 9.1\%). 50.9\% (28) reported their organizations' strategy is to proactively open new markets, also with using novel technologies, while $10.9 \%$ (6) reported to only address stable markets with using established technologies. Concerning employee numbers, the organizations were categorized into four classes: i) very small (up to 50) with 20 (36.4\%); ii) small (51 to 250 ) with $12(21.8 \%)$; iii) medium (251 to 1,000$)$ with 10 $(18.2 \%)$, large $(>1,000)$ with $11(20 \%)$, and $2(3.6 \%)$ non-respondents (NR). Most respondents had the job titles CIO $(14 ; 25.5 \%)$ or CEO $(13 ; 23.6 \%)$; others were middle managers $(10 ; 18.2 \%)$, CGOs $(8 ; 14.5 \%)$, CFO $(1 ; 1.8 \%)$, and $9(16.4 \%)$ in other positions. They were asked how long they had been working in their current organization and current position. Concerning overall membership, the span was 1 (MIN) to 32 years (MAX) $(\mathrm{AVG}=12.109 ; \mathrm{SD}=9.150)$. The job activity reached from $1(\mathrm{MIN})$ to 30 years $(\mathrm{MAX})(\mathrm{AVG}=8.23$; $\mathrm{SD}=$ $7.451)$. Of the sample organizations, $37(67.3 \%)$ had an own IT department; there was an IT outsourcing rate of up to $25 \%$ for 26 companies $(47.3 \%) ; 26 \%$ to $50 \%$ for 9 $(16.4 \%), 51 \%$ to $75 \%$ for $5(9.1 \%)$, and 76 to $100 \%$ for $16,4 \%$ (else NR). Further, 34 organizations $(61.8 \%)$ had an official CIO, $5(9.1 \%)$ a non-official CIO, and $29.1 \%$ no CIO. $34.5 \%$ (19) reported to have a CGO/CSO.

\section{Results}

\subsection{General sustainability aims, usage and administrative structures}

Concerning sustainability standards and product procurement of all 55 sample companies, $67.3 \%$ (37) subscribed to an official sustainability standard (14 NR), $45.5 \%$ (25) followed a certified standard (e.g. ISO 14001) (17 NR), and 67.3\% (37) procured and used products with an environmental seal (e.g. der Blaue Engel) (17 NR). These standards, for instance, regulate water $(23 ; 41 \%)$, electricity $(24 ; 43.6 \%)$, paper $(27$; $49.1 \%)$, additional resources $(22 ; 40 \%)$, or IT use (14; $25.5 \%)$. Of the 8 companies without sustainability 
standard, $87.5 \%$ (7) intended to soon subscribe to sustainability standard, of which $42.9 \%$ (3) intended to get a specific sustainability standard certificate.

To document how sustainability translates into organizational practices, we asked about the companies' energy use, waste, emissions, and car use management practices. While $87.3 \%$ (48) followed or introduced means to lower their energy consumption, $72.7 \%$ (40) already actively and regularly inspected their general energy consumption. For $60 \%$ (33), these energy saving means included the use of technical equipment, and for $58.2 \%$ (32) also the use of non-technical means. Moreover, $58.2 \%$ (32) of all sample companies used renewable energy, while $12.7 \%$ (7) planned to use such. Of the sample companies, $69.1 \%$ (38) reported to have and $9.1 \%$ (5) to plan adopting a waste management system. Regarding greenhouse gas emissions reduction, $45.5 \%$ (25) already achieved actual reductions, whereas $21.8 \%$ (12) planned to reduce greenhouse gas emissions. One specifically reported means was car use; distinguished between corporate and private car use. $36.4 \%$ (20) organizations encouraged employees to reduce private car use $(18.2 \% ; 10$ intentions). For corporate cars, $30.9 \%$ (17) encouraged and $21.8 \%$ (12) intended to encourage employees to use these less.

\subsection{Green IS administration and relevance}

4.2.1. Green IS usage and administrative support. We asked about use of Green IS in the organization. Of the 55 validly filled-out surveys, $11(20 \%)$ respondents reported their organizations already used Green IS, while $4(7.3 \%)$ planned to use Green IS. Of these 11 organizations, $81.8 \%$ (9) fully agreed or agreed on

Table 2. Reasons for non-adoption of Green IS

\begin{tabular}{|c|l|}
\hline Responses & Reason for Green IS non-adoption \\
\hline $40.9 \%(9)$ & $\begin{array}{l}\text { No, too little relevance - IT and the IT department } \\
\text { consume too few resources compared to the rest of the } \\
\text { organization (e.g. production lines). }\end{array}$ \\
\hline $18.2 \%$ (4) & $\begin{array}{l}\text { A lack of resources - the IT department has } \\
\text { insufficient resources (esp. time and personnel) to } \\
\text { initiate Green IS initiatives. }\end{array}$ \\
\hline $13.6 \%$ (3) & $\begin{array}{l}\text { No clear benefit - Green IS is not part of top } \\
\text { management's agenda, since its benefits are unclear. }\end{array}$ \\
\hline $9.1 \%$ (2) & $\begin{array}{l}\text { No suitable products or services - organizations are } \\
\text { bound to use mainstream and established product and } \\
\text { service providers, for reasons of product performance } \\
\text { and service quality. }\end{array}$ \\
\hline $9.1 \%$ (2) & $\begin{array}{l}\text { No demand - a lack of legislative, societal, or } \\
\text { customer demand; or customers ask for cheap and } \\
\text { reliable rather than sustainable products and services. }\end{array}$ \\
\hline $4.5 \%$ (1) & $\begin{array}{l}\text { Other IT priority - the IT department must focus on } \\
\text { other aspects, e.g. customer acquisition and the } \\
\text { meeting of service levels. }\end{array}$ \\
\hline $4.5 \%$ (1) & $\begin{array}{l}\text { No potential - it is not possible to save additional } \\
\text { resources (e.g. in R\&D activities). }\end{array}$ \\
\hline$N o t e ~ \mathrm{~N}=22$ &
\end{tabular}

aiming at being a Green IS leader. Of these, $72.7 \%$ (8) reported their top management was highly committed or committed to use Green IS; in $90.1 \%$ (10) corporate procurement decisions. Of the sample, $45.5 \%$ (5) reported to encourage employees to use IT assets sustainably. In $54.5 \%$ (6) of these organizations, the CIO was responsible for coordinating Green IS activities, while $36.4 \%$ (4) defined a specific role to support organizational Green IS activities. Further, $18.2 \%$ (2) of the organizations had not yet, but were about to introduce such a position.

4.2.2. Reasons for non-adoption. We also asked about reasons why organizations did not (yet) undertake a sustainability initiative. Of the respondents, 4 (7.3\%) provided insights. Two of them specifically mentioned sustainability is "Not on the board's agenda" and "At the bottom of management priority list." Another reason, as mentioned by two respondents, was sustainability would not be a customer requirement or not a strong one. The absence of "short-term benefit in relation to costs." was a third reason.

The reasons from $40 \%$ (22) of organizations not to pursue Green IS activities or initiatives were more diverse and fall into seven classes (see Table 2). For most $(40.9 \%)$ organizations, IS sustainability would have too little impact on the organization's overall sustainability outcome. Further, $18.2 \%$ would like to use Green IS, but either lacked in the resources or could not communicate the benefits to top management. Notably, some companies actively used sustainable products (e.g. Fairphone), but reverted back to using mainstream ones, for reasons of higher product and service quality.

\subsection{Status of specific Green IS actions}

For reasons of better comparability, we chose to report on specific Green IS initiatives of the 11 organizations using Green IS by distinguishing between actions that aim at benefits for the natural environment, society, the organization, and employees [32]. Here, we did not report on initiatives that specifically address the natural environment, since this is considered as initiatives' overall goal and is separately reported on.

4.3.1. Societal level actions. Two questions covered this level. We asked Green IS using organizations, i) if they selected vendors according to sustainability criteria and ii) if they donate equipment they no longer require. $54.5 \%$ (6) selected and 9.1\% (1) had selected vendors along sustainable criteria, and also $54.5 \%$ (6) donated and $18.2 \%$ (2) had donated unused equipment.

4.3.2. Organizational level actions. Concerning the broad spectrum of these initiatives, we distinguished 
between reporting on i) equipment use, ii) IT equipment use, iii) IT management, iv) energy management, and v) resource management.

Equipment use: All 11 organizations (100\%) reported on recycling equipment (printers and other hardware) and using multipurpose equipment; $81.8 \%$ (9) used products fully or partially made from recycled components; $90.9 \%$ (10) collected recyclable materials; $63.6 \%$ (7) used or had used trade-in and exchange options for old hardware, while $18.2 \%$ (2) of organizations were considering this option.

IT equipment use: Of all 11 companies using Green IS, $81.8 \%$ (9) reported on i) consolidating and virtualizing of servers, ii) virtualizing desktops, and iii) constantly updating their data center(s); 90.9\% (10) reported suitably disposing computing equipment; and $63.6 \%$ (7) reported they were exchanging or exchanged monitors for more energy-efficient ones.

IT management. $90.9 \%$ (10) of organizations increased their IT hardware's product lifecycle, while remaining organizations planned to do the same; $54.5 \%$ (6) reported using and $18.2 \%$ (2) intending to use IT for ecological facility management; $45.5 \%$ (5) actively perform energy-efficiency analyses of IT equipment; $27.3 \%$ (3) had a sustainability board.

Energy management. Most of the organizations $(90.9 \%$; 10) used renewable energy; $63.6 \%$ (7) also used energy management systems and/ or selected software along energy-efficiency criteria. A minority $(27.3 \% ; 3)$ reported to reuse or to have reused IT equipment heat for other purposes (e.g. heating of facilities) $(9.1 \% ; 1)$.

Resource management. The use of recycled paper is one of the most frequently named Green IS resource management means, implemented in $90.9 \%$ (10) of all organizations using Green IS, followed by non-use of devices made of or with hazardous materials $(72.7 \% ; 8)$; $36.4 \%$ (4) used or had used $(9.1 \% ; 1)$ environmental control systems (e.g. checked or had checked gas emissions or water quality).

4.3.3. Individual level actions. The use of Green IS also influences every employee in an organization [32]. We found employees of $90.9 \%$ (10) of all organizations utilized Green IS employed teleworking or videoconferencing instead of physical travelling to a meeting. The same number of respondents reported to use digital rather than physical documents. Addressing employee printer use seems to be key, since $90.9 \%$ (10) of organizations encourage their employees to print double-sided, and $81.8 \%$ (9) limited employee printer use by consolidating and reducing the number of devices, 54.5\% (6) monitored employees' printer use. We also found $72.7 \%$ (8) had or had had a campaign to make employees aware of Green IS-related topics, while $18.2 \%$ (2) intended to take a campaign up.

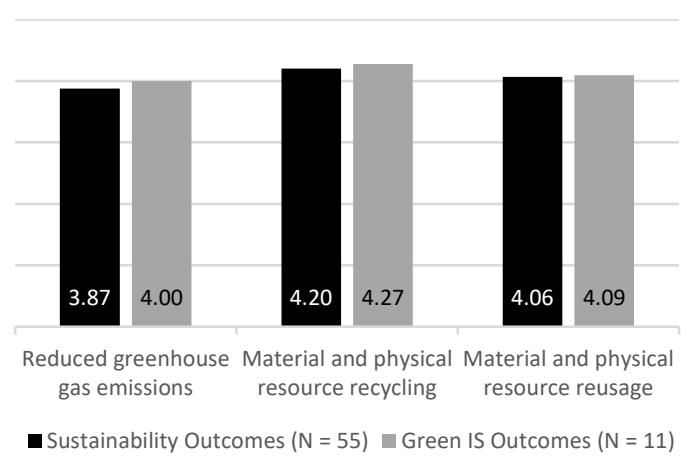

Figure 1. Average scores for natural environment outcomes on Likert scale ranging from 1 (very negative) to 5 (very positive)

\subsection{Sustainability and Green IS outcomes}

We asked if organizations' sustainability and Green IS actions had negative, positive, or no or neutral effects, and categorized results into four levels [32].

4.4.1. Natural environment-level outcomes. We measured these in terms of the recycling of materials, the use of recycled materials, and greenhouse gas emissions. For all three items, we derived slightly better average values for Green IS outcomes than for general sustainability outcomes (see Figure 1).

For reducing greenhouse gas emissions, the numbers also suggest fairly positive outcomes on the natural environment (positive or very positive general sustainability outcomes for $60 \%$ organizations, and $72.7 \%$ Green IS outcomes). We observed a trend toward conserving natural resources, via the recycling of used materials and physical resources (positive or very positive outcomes for general sustainability for $56.4 \%$ of organizations, and $81.8 \%$ outcomes for Green IS), the reuse of recycled materials (positive or very positive general sustainability outcomes for $61.8 \%$ organizations, and $72.7 \%$ Green IS outcomes). Notably, on average $33.3 \%$ (general sustainability) and $39.4 \%$ (Green IS) outcomes had no or a neutral effect on the natural environment.

4.4.2. Society-level outcomes. We measured these in terms of social acceptance, legislative compliance, increased transparency, and influence on competitors. We derived mixed average values for Green IS outcomes, as for general sustainability outcomes (see Figure 2). Three specific results are worth highlighting: First, although observed for only one organization $(1.8 \%)$, general sustainability can negatively affect social acceptance (positive or very positive effect for $58.2 \%$, and not observed for Green IS). Second, the 


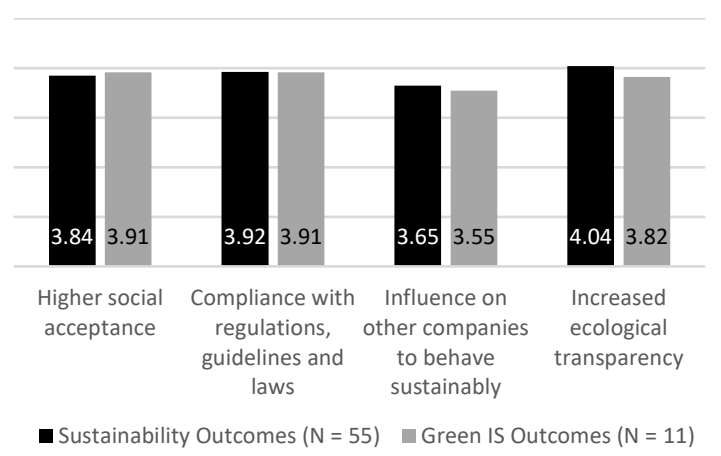

Figure 2. Average scores for societal outcomes on Likert Scale ranging from 1 (very negative) to 5 (very positive)

societal outcome to influence other organizations to behave sustainably was rather low. $49.1 \%$ report a neutral or no effect of general sustainability, and $63.6 \%$ for Green IS. Third, sustainability's overall social visibility was likewise very low, with an average of neutral or no effect of $34.1 \%$ for general sustainability and $47.7 \%$ for Green IS.

4.4.3. Organizational-level outcomes. We measured these categories of resource and energy procurement and use as well as respective costs, for which we also highlight three results (see Figure 3 for average value comparison). First, we found general sustainability outcomes may also have negative consequences for organizations. 5.5\% reported higher repair costs, 3.6\% longer processing times, and $1.8 \%$ uncertainty concerning energy use forecast. Second, $65.5 \%$ reported positive or very positive general sustainability outcomes for reduction of general resources consumed, and $67.3 \%$ reduced energy consumption. Third, we ascertained Green IS positively influenced energy consumption, and the cost of the energy used (both 90.9\%). However, it may often influence processing times $(63.6 \%)$ as well as repair costs and performed work (both $45.5 \%$ ) neutrally or not positively.

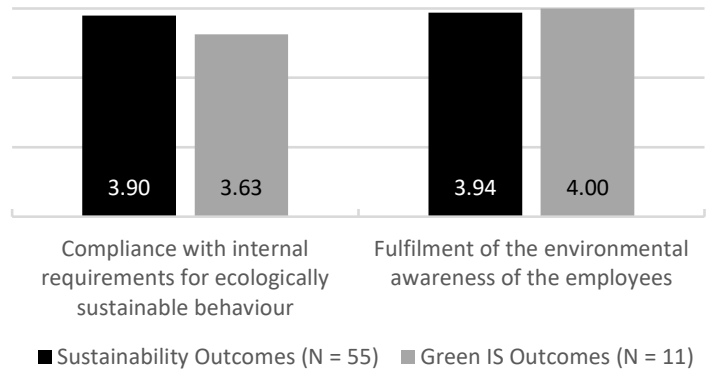

Figure 4. Average scores for individual outcomes on Likert Scale ranging from 1 (very negative) to 5 (very positive)

4.4.4. Individual-level outcomes. We measured employee compliance, and awareness of sustainability, and Green IS (see Figure 4). General sustainability actions were reported to positively influence both dimensions. $70.9 \%$ reported positive or very positive outcomes on employee awareness, and $60 \%$ on compliance with sustainable behaviors. Green IS seems to have only a medium influence on both aspects, since $36.4 \%$ of the respondents reported no or a neutral effect.

\section{Discussion}

The results of our documentative study provide detailed insights into organizational sustainability and Green IS practices, their outcomes, but also why organizations' choose to not pursue sustainability, and Green IS endeavors. We will now discuss selective findings, and compare sustainability and Green IS outcomes, before noting limitations, paths for further research, and the contributions of this study.

\subsection{Sustainability and Green IS Outcomes}

We discuss three findings in detail. First, organizations that use Green IS have a top management

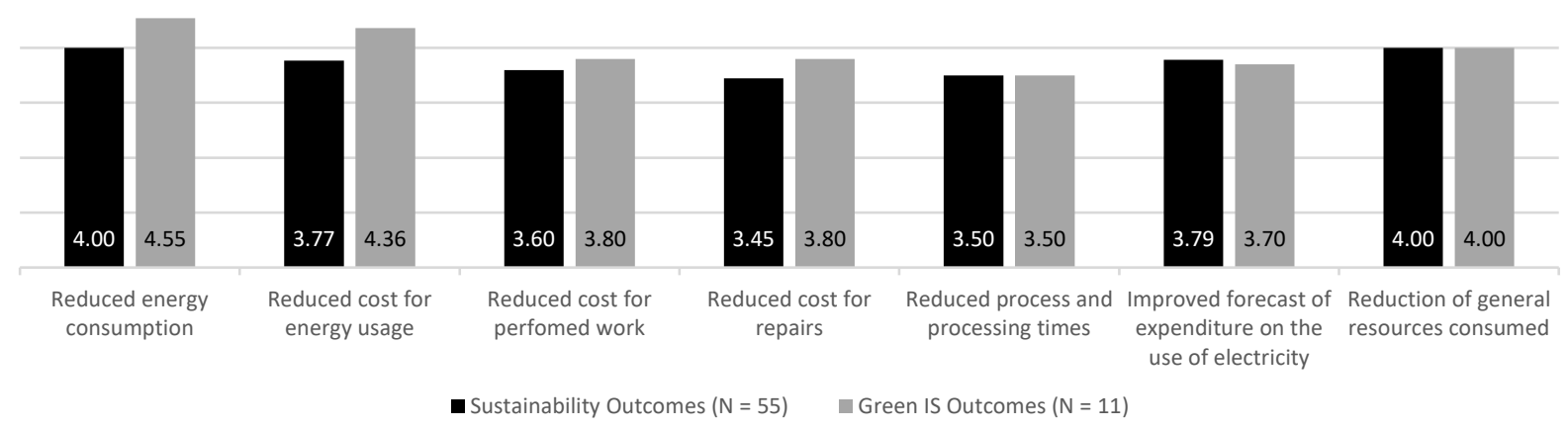

Figure 3. Average scores for organizational outcomes on Likert Scale ranging from 1 (very negative) to 5 (very positive) 
that is very committed to it. Thus, sustainability and Green IS efforts seem to be introduced and progressed in a top-down way [5]. The conceptualized individual level [32], hence, seems to be of primary importance in the outcome and not the introduction phase.

Second, many sustainability and Green IS initiatives had no or a neutral effect. Some reasons may be sustainability technologies and Green IS i) require a long time for their effects to materialize [35], ii) are not as sustainable or their outcomes are not as sustainable as desired [22], or iii) still require different measurement sets [32]. None of these potential reasons is easily be explained or eliminated. Researchers could seek for detailed insights into i) long-term effects and outcomes, ii) the production and conception of Green IT and Green IS, or iii) other likely benefits, including intangible ones.

Third, we found $40.9 \%$ of organizations that did not use Green IS reported non-use because of foreseeing insignificant benefits. They argue that departments, such as manufacturing and production, contribute far more to organizational sustainability balance. A reason for neglecting Green IS's benefits may be organizations' understanding of Green IS as to only save energy. They neglect that Green IS also includes IS support of organizational production processes and the use of ISbased environmental management systems [18].

\subsection{Sustainability and Green IS Outcome Differences}

5.2.1. Natural environment-level outcomes. As other researchers suggested [9], we confirmed Green IS positive impacts on the "end of the pipe" of products. Especially for innovations, which require significant amounts of resources to produce and operate, the sample organizations reported that Green IS reduces greenhouse gas emissions and increases the recycling of material and physical resources. This indicates the benefits to the natural environment of consolidating IT (e.g. servers and data centers) and the recycling of unused hardware.

5.2.2. Society-level outcomes. Our results indicate that, while Green IS had positive outcomes for organizations, general sustainability had a more positive impact overall. This is especially visible in increased ecological transparency and influence on other organizations to behave sustainably. Both results may originate from Green IS being the single organizational sustainability initiative of the entire spectrum in organizations. If IT is of little strategic importance in an organization, for instance, compared to production and manufacturing, its visible contribution is - similarly - of lower importance.
Notably, Green IS had a slightly higher impact on social acceptance compared to sustainability initiatives generally. This may be an indicator that Green IS can contribute to selectively raise awareness and acceptance, although other sustainability factors are more important for some organizations. An organization may, for instance, decide to reduce the number of meetings for which its employees must travel to other locations [35]. This highly visible decision may lead to higher social acceptance of the organization and its sustainability decisions, as it is yet more accustomed to travel to customer meetings.

5.2.3. Organizational-level outcomes. Regarding organizational outcomes, we highlight three results. First, Green IS is reported to clearly lower the amount of energy consumed as well as its costs. This may be explained by observations that organizations consolidate IT hardware, or replace it by more energyefficient hardware. Moreover, it does not only highlight Green IT as first step [18], but cores a Green IS practice set [11]. Second, Green IS was reported to reduce repair costs. This may be unexpected, since extending the lifecycle of IT as the underlying Green IS practice is commonly also associated with the cost of repairing and replacing malfunctioning hardware. A potential reason for this observation may be the necessary communication of extending IT lifecycles to users, leading to the more careful treatment of hardware. Apparently contradictory to the first findings, we commented on respondents' reporting on a worse forecast of expenditures for electricity use. This may be explained through changes in electricity use dynamics. For instance, we assume that before introducing Green IS, energy use was fairly constant (e.g. servers were running permanently, monitors and computers stayed switched on). The introduction of energy-saving software, or hardware automatically switches to idle or energy-saving modes, and cause demand-based electricity use, that is harder to predict.

5.2.4. Individual-level outcomes. On the individual layer, the sample organizations reported a far worse compliance with Green IS behaviors in contrast to general sustainability behaviors. Two facets of Green IS innovation may explain this. Green IS use, continued, and Green IS-related behaviors are significantly influenced by the respective technologies' ease-of-use [5] as well as a personal benefit [35]. If none is sufficient, neither top management as decision-making unit to use Green IS, nor individual users will use it. 


\subsection{Limitations, Further Research, and Contributions}

This study has limitations. Notably, we only surveyed a small sample size. Though surveys among top-managers commonly have small response rates [19], it greatly limits our results' generalizability. Further, we only found a fairly small number of organizations that publicly reported on using sustainable and ecologically friendly products. This also negatively influences our results' generalizability to organizations using Green IS.

Moreover, as most respondents were not just CIOs but also came from non-IT related positions, they may have been unaware of Green IS actions, or uninvolved in respective sustainability initiatives. This further biases these studies' results. We, thus, encourage further research that i) comparatively investigates organizations whose offerings rely on IS and that only use IS for support, and ii) specifically addresses CIOs, and CGOs.

We call to address our study's limitations but also to build on our results. For instance, we found certain organizations stopped using Green IS, and have suggested reasons for this. In addition, while we found positive sustainability and Green IS initiative outcomes, we suggest shedding light on the clear assignment which initiatives result in which benefits - as well as on the underlying innovation and adoption processes.

Our work is also beneficial for practitioners. The specific insights may serve as productive arguments to introduce Green IT, as we also found some organizations do not pursue Green IS, as its benefits are unclear to top management. Our results may also provide fruitful arguments to advance both, sustainability and Green IS initiatives, and extending these initiatives aimed at outcomes to additional levels.

\section{Conclusion}

As environmental issues are becoming increasingly pressing to the global community, organizations must consider sustainability aspects. Adopting sustainable innovations such as Green IS is one way to address this challenge. We addressed shortcomings in contemporary research by providing a comprehensive documentation of both sustainability and Green IS actions, and their respective outcomes. We found that Green IS' outcomes can substantially help to reduce energy consumption and greenhouse gas emissions, although few organizations have embraced Green IS as part of their sustainability portfolio so far. These insights, which are also useful for practitioners, provide a strong basis for further research. In particular, initiatives that have no or neutral effects should be further researched as well as organizational reasons for stopping the use of Green IS.

\section{References}

[1] Chen, A.J., R.T. Watson, M.-C. Boudreau, and E. Karahanna, "Organizational adoption of green IS \& IT: An institutional perspective", ICIS 2009 Proceedings, (2009).

[2] Corbett, J., "Designing and using carbon management systems to promote ecologically responsible behaviors", Journal of the Association for Information Systems 14(7), 2013, pp. 339.

[3] Dao, V., and T. Abraham, "An Exploratory Empirical Examination of the Integrated Sustainability Framework via Case Study", AMCIS 2018 Proceedings, (2018), 10.

[4] Dedrick, J.L., "Green IS: Concepts and issues for information systems research", Communications of AIS 27, 2010.

[5] Deng, Q., and S. Ji, "Organizational Green IT Adoption: Concept and Evidence”, Sustainability 7(12), 2015, pp. 16737-16755.

[6] Deng, Q., S. Ji, and Y. Wang, "Green IT Practice Disclosure: An Examination of Corporate Sustainability Report in IT Sector", ICIS 2015 Proceedings, (2015).

[7] Erek, K., N.-H. Schmidt, R. Zarnekow, and L.M. Kolbe, "Sustainability in information systems: assortment of current practices in IS organizations", AMCIS 2009 Proceedings, (2009).

[8] Hameed, M.A., S. Counsell, and S. Swift, "A conceptual model for the process of IT innovation adoption in organizations", Journal of Engineering and Technology Management 29(3), 2012, pp. 358-390.

[9] Hart, S.L., "A Natural-Resource-Based View of the Firm", The Academy of Management Review 20(4), 1995, pp. 986.

[10] Hilpert, H., J. Kranz, and M. Schumann, “An Information system design theory for green information systems for sustainability reporting-integrating theory with evidence from multiple case studies", ECIS 2014 Proceedings, (2014).

[11] Ijab, M.T., A. Molla, and V.A. Cooper, "A theory of practice-based analysis of Green Information Systems (Green IS) use", ACIS 2011 Proceedings, (2011).

[12] IPCC, Climate Change 2014: Synthesis Report. Contribution of Working Groups I, II and III to the Fifth Assessment Report of the Intergovernmental Panel on Climate Change, Geneva, Switzerland, 2014.

[13] Jenkin, T.A., J. Webster, and L. McShane, “An agenda for 'Green' information technology and systems research", Information and Organization 21(1), 2011, pp. 17-40. 
[14] Karanasios, S., V. Cooper, H. Deng, A. Molla, and S. Pittayachawan, "Antecedents to greening data centres: A conceptual framework and exploratory case study", ACIS 2010 Proceedings, (2010).

[15] Kuo, B.N., and G.N. Dick, "Organizational Green IT: It seems the bottom line rules", AMCIS 2010 Proceedings, (2010).

[16] Larrán Jorge, M., J. Herrera Madueño, Y. Calzado, and J. Andrades, "A proposal for measuring sustainability in universities: a case study of Spain”, International Journal of Sustainability in Higher Education 17(5), 2016, pp. 671-697.

[17] Leidner, D.E., B. Kettinger, E. Gonzalez, and M. Milovich, "Introduction to the HICSS-50 Minitrack on Practice-based IS Research", Proceedings of the 51st Hawaii International Conference on System Sciences, (2018), 5064.

[18] Loeser, F., "Green IT and Green IS: Definition of constructs and overview of current practices", AMCIS 2013 Proceedings, (2013).

[19] Loeser, F., J. Recker, J. vom Brocke, A. Molla, and R. Zarnekow, "How IT executives create organizational benefits by translating environmental strategies into Green IS initiatives", Information Systems Journal 27(4), 2017, pp. 503-553.

[20] Lubin, D.A., and D.C. Esty, "THE SUSTAINABILITY IMPERATIVE", Harvard Business Review 88(5), 2010, pp. $42-50$.

[21] Lunardi, G.L., A.P.F. Alves, and A.C. Salles, "Green IT Maturity: developing a framework based on practices and actions", CONF-IRM 2013 Proceedings, (2013).

[22] Lunardi, G.L., D.B. Dolci, A.C. Salles, and A.P.F. Alves, "Green IT: an Empirical Study regarding Organizational Actions and Impacts on Environmental Performance.”, CONF-IRM 2015 Proceedings, (2015).

[23] Malhotra, A., N.P. Melville, and R.T. Watson, "Spurring impactful research on information systems for environmental sustainability", MIS quarterly 37(4), 2013, pp. 1265-1274.

[24] Massachusetts Institute of Technology (Cambridge, Mass.), The future of coal: options for a carbon-constrained world : an interdisciplinary MIT study, MIT, Cambridge, 2007.

[25] Molla, A., A. Abareshi, and V. Cooper, "Green IT beliefs and pro-environmental IT practices among IT professionals", Information Technology \& People 27(2), 2014, pp. 129-154.

[26] Molla, A., and V. Cooper, "GREENING DATA CENTRES: THE MOTIVATION, EXPECTANCY AND ABILITY DRIVERS”, ECIS 2014 Proceedings, (2014).
[27] Molla, A., S. Pittayachawan, and B. Corbitt, "Green IT diffusion: an international comparison", Green IT Observatory, RMIT School of Business IT and Logistics, 2009.

[28] Molla, A., S. Pittayachawan, B. Corbitt, and H. Deng, "An international comparison of Green IT diffusion", International Journal of e-Business Management 3(2), 2009.

[29] Nishant, R., T.S.H. Teo, and M. Goh, "Sustainable Information Systems: Does It Matter?”, PACIS 2013 Proceedings, (2013), 88.

[30] Radu, L.-D., "Determinants of Green ICT adoption in organizations: A theoretical perspective", Sustainability 8(8), 2016, pp. 731.

[31] Sayeed, L., and S. Gill, "Implementation of Green IT: Implications for a dynamic resource", AMCIS 2009 Proceedings, (2009).

[32] Schmermbeck, H., “On Making a Difference: Towards an Integrative Framework for Green IT and Green IS Adoption", Proceedings of the 52nd Hawaii International Conference on System Sciences (HICSS), (2019).

[33] Sedera, D., S. Lokuge, B. Tushi, and F. Tan, "Multidisciplinary Green IT Archival Analysis: A Pathway for Future Studies", Communications of the Association for Information Systems 41(1), 2017, pp. 674-733.

[34] Seidel, S., J. vom Brocke, and J.C. Recker, "Call for action: investigating the role of business process management in green IS", Sprouts: Working Papers on Information Systems 11(4), 2011.

[35] Simmonds, D.M., and A. Bhattacherjee, "Smart Systems, Smarter Living: An Empirical Study of the Building Automation System in Organizations", Proceedings of the 2015 Pre-ICIS Workshop, (2015).

[36] Wang, X., S. Brooks, and S. Sarker, "Understanding Green IS Initiatives: A Multi-theoretical Framework", CAIS 37, 2015, pp. 32.

[37] Wang, X., S. Brooks, and S. Sarker, "A Review of Green IS Research and Directions for Future Studies", Communications of the Association for Information Systems 37, 2015.

[38] Watson, Boudreau, and Chen, "Information Systems and Environmentally Sustainable Development: Energy Informatics and New Directions for the IS Community", MIS Quarterly 34(1), 2010, pp. 23.

[39] Yang, Z., J. Sun, Y. Zhang, and Y. Wang, "GREEN INFORMATION SYSTEMS, GREEN CULTURE AND GREEN INNOVATION EFFECTIVENESS: A TRIAD MODEL", PACIS 2016 Proceedings, (2016), 19. 